\title{
建筑给水排水设计中绿色环保理念的应用
}

\author{
李硕 \\ 省纺织工业设计研究院 \\ DOI:10.18686/bd.v2i7.1526
}

[摘要] 当前我国在经济发展的过程中消耗了大量的资源, 这也对生态环境带来巨大压力。因此环保节能也逐渐受到了人 们的关注和重视。而在建筑给排水设计中,绿色环保理念的应用也日益广泛,该设计能够有效推动建筑行业的可持续发展。 [关键词] 给排水设计; 绿色环保; 应用

绿色环保理念下, 建筑给排水设计能够有效减少水资 源的消耗量,但是从当前的发展状况来看,我国的建筑给排 水资源利用率相对较低,水体浪费比较严重,因此我们必须 要在建筑给排水设计中充分考虑资源的充分利用, 从而推 动建筑行业的健康发展。

1 建筑给水排水设计中绿色环保理念的重要性分析

当前我国的水资源相对较为贵乏, 在这一背景下, 人们 越来越重视环保。人们已经意识到了环境问题的危害。所以 建筑给排水设计中, 一定要做好节能工作。做好给排水设计, 这一方面能够有效提高工程的经济效益, 另一方面还可缓 解我国城市水资源供需方面的矛盾, 降低建筑工程的成本 投人。因此在建筑给排水设计中一定要积极贯彻绿色环保 理念。

\section{2 建筑给水排水资源利用现状}

当前,我国城市建设速度日益加快,城市建设规模不断 扩大, 城市人口数量越来越多, 因此建筑工程的数量也在不 断增多。为了更好地满足人们对水资源的需要, 就应确保水 资源的及时足量供应, 自来水企业应积极学习和引进先进 的水处理和供水技术,从而有效提高供水的效率。此外,还应 采取有效措施对建筑给排水系统进行不断改进和完善, 在 节能环保理念的基础上,进行建筑给排水设计, 以此来更为 充分地利用水资源,控制水资源浪费问题。保证建筑给排水 系统节水节能的整体效果。但是在建筑给排水系统的设计 中还存在着十分明显的问题。

2.1 水资源浪费较为严重

建筑给排水系统中, 水资源浪费现象较为严重, 出现这 一问题主要是人为因素的影响, 如人们并未树立较强的节 水意识, 配水器具和卫生洁具的节水性能较差, 出现了超压 出流的问题。建筑给排水设计的过程中, 设计人员没有科学 利用和贯彻节能环保的理念, 并且也未对雨水和中水没有 采取有效措施予以回收和利用。

2.2 给水管网压力过大

建筑给水系统涌水量较大, 无法实现节水的目标, 因此 建筑给水管网需要承受较大的给水压力, 该情况也容易出 现建筑给水管网压力达不到标准的现象, 进而使高层建筑 的给水质量无法得到保证。

\section{3 给水零部件与卫浴设备的节水性能较差}

建筑给排水系统设计中, 没有充分贯彻节水节能的思 想, 所以在设计的过程中, 没有充分考虑到给水零部件的节 水性能,进而影响了设计的节水效果,增加了水资源的消耗, 无故浪费了较多的水资源。

\section{3 绿色环保理念在建筑给水排水设计中的应用}

\section{1 科学处理生活污水和雨水}

我国经济发展水平不断提高, 水资源短缺也日益严重, 人们的生产生活中会排放很多污水, 这些污水要经过污水 管网的收集,之后经过污水处理厂的多步骤处理,确保水质 达标后才可排放到河道内。这种处理方式可有效避免河道 水体污染问题。雨水分流能够有效地保证雨水的收集,同时 也为雨水的集中管理和排放提供了诸多的便利, 减少了污 水处理厂的污水处理工作, 从而对城市环境也起到非常明 显的改善作用,为人们提供了更加安全舒适的生活环境。水 资源的利用效率也在这一过程中得到了显著的提升, 建筑 生活区的用水成本也大大降低。

经过处理的污水可满足国家相关标准的要求, 其能够 应用于工业生产和农业生产中, 还可起到补给地下水的作 用。当前我国水资源现状不容乐观,所以在建筑给排水系统 设计过程中应积极地应用最新的污水处理技术, 以确保城 市污水的处理效果,污水和雨水在处理后可多次使用,如此, 就可以有效控制水资源的浪费,缓解水资源的供需矛盾。

3.2 充分利用太阳能集热装置

建筑给排水绿色节能设计中, 应充分利用太阳能资源, 减少资源消耗。因为太阳能是一种可再生能源, 同时其在应 用的过程中不会对生态环境构成严重的污染, 所以在建筑 给排水设计中, 应科学利用太阳能, 这样可以更好地确保建 筑内部热水的及时充分供应, 减少天然气和电能的消耗, 从 而达到节能的目的。

此外, 太阳能热水器应用也十分广泛, 因此科学利用太 阳能热水器, 也能够改善建筑给排水的节能效果。与此同时, 在设计中, 为了更好地保证集热器的有效应用, 在气温较低 的冬季或海拔较高的地区, 还应采取有效措施保证集热管 的正常使用,减少集热管内部的热能消耗。在建筑给排水设 计中, 只有合理采用绿色环保节能设计的理念, 才能更好地 
完善建筑给排水系统的节能效果。

3.3 积极采用全新的节水设备

建筑给排水设计过程中, 应用绿色节能环保理念一定 要以高质量的节水设备为基础,采用最新的管材和闵门。传 统的给水管道主要采用镀锌钢管, 这种钢管在长时间使用 后,会出现较为严重的腐蚀问题,容易出现漏水现象, 会降低 水体的质量,无法保证居民的正常用水。所以,建筑给排水设 计中应用绿色环保理念时, 必须要应用质量性能有保障的 管材,管材本身应具备较好的耐久性,同时也应具有良好的 抗腐蚀性。此外,在建筑给排水设计工作中,对于高层建筑排 水管道的选择也需予以高度重视, 通常应选择具有消声功 能的螺旋管,该管可有效控制噪声。

3.4 选择节能性强的配件

应用节能配件的过程中, 一定要充分考虑建筑给排水 系统运行的实际, 选择符合要求的节能型配件, 进而能够更 好地体现绿色环保节能理念的优势。建筑排水系统设计时, 要采用节水型洁具,如选择节水型淋浴喷头,并且严格控制 水压,从而在满足人们用水需求的同时,也可有效减少资源 的消耗和浪费。此外,节能型配件在应用的过程中还可以很 好地维持管道内部的水压平衡, 完善建筑给排水的节能效 果。

\section{4 应用实例分析}

\section{1 工程概况}

某工程位于市区,地上部分 A 楼共 15 层, 高度在 $50 \mathrm{~m}$ 以下, $\mathrm{B}$ 楼 2 层, 高度为 $10.9 \mathrm{~m}, \mathrm{C}$ 楼共 14 层, 总高度在 $50 \mathrm{~m}$ 以下。 $\mathrm{AB}$ 两楼地下一层, $\mathrm{C}$ 楼地下三层, 主要为宿舍、会议室 和接待室等。

\section{2 合理应用节能措施}

在综合楼的宿舍和卫生间内设置了热水供应, 按照相 关标准的要求,生活热热源采用太阳能,这种能源是可再生 能源, 同时能源应用中不会对环境构成污染。项目生活热水 采用太阳能作为热能来源, 将空气源热泉作为辅助热源, 该 项目日热水需求量为 $29.52 \mathrm{~m} 3 / \mathrm{d}$, 对集热器的面积进行科学 计算后, 确定太阳能集热器的具体类型, 太阳能集热器和空 气热葲组成热水机组, 热水储水装置和循环原应设置在北 斗七星应用中心屋顶, 采用热水水箱作为生活热水的储存 装置,同时采用热水变频百对热水进行二次加压。

生活热水与生活冷水分区完全相同。热水循环采用感 官立管强制机械循环防水, 回水管的温度探测器探测水温 在 55 度以下, 热水系统循环原应处于开启状态, 以此保证管 道内的水温始终在 55 度以上。
4.3 选择节水型的设备和材料

使用全新的高品质管材和阀门是保证节能效果的一个 关键要素,该项目冷热水全部采用室外埋地的方式,且给水 管应用 PSP 管,室内使用干管,立管和公共卫生间支管采用 钢塑复合管,宿舍和卫生间的支管采用 PPR 管,阀门的质量 对用水的质量有着十分显著的影响。本项目中 $\mathrm{DN}<50$ 时, 采用截止阀, $\mathrm{DN} \geqslant 50$ 时, 使用闸阀, 阀芯的材质主要为不锈 钢或铜。

给水器具中, 卫生器具与人们的生活关系最为密切, 卫 生器具的性能直接影响了节水的效果。该项目中全部采用 节水效率为 2 级的卫生器具。冲洗量如表 1 所示。

表 1 冲洗水量

\begin{tabular}{|l|l|l|l|l|l|}
\hline 用水器具 & 淋浴器 & $\begin{array}{l}\text { 座便器 } \\
\text { 冲洗阀 }\end{array}$ & $\begin{array}{l}\text { 大便器 } \\
\text { 冲洗阀 }\end{array}$ & $\begin{array}{l}\text { 小便器 } \\
\text { 冲洗 阀 }\end{array}$ & $\begin{array}{l}\text { 陶瓷片 } \\
\text { 封水嘴 }\end{array}$ \\
\hline 冲洗 水量 $/ \mathrm{L}$ & 0.12 & $3.5 / 5.0$ & 5.0 & 3.0 & 0.125 \\
\hline
\end{tabular}

经过处理之后的中水可用于冲则所, 室外绿化的浇灌 和道路的喷酒等,其也能起到非常好的节水作用。该项目当 中采用了雨水收集装置, 同时对市政中水进行了充分的利 用,雨水收集首先面对屋面的雨水,由于屋面雨水受到的污 染较少, 处理也相对容易。经过初期处理的雨水, 在储水模块 池当中有非常多的时间来完成沉淀工序, 沉淀后雨水经过 过滤和消毒就可以用于道路喷酒以及车库清洗等多个方 面。

4.4 利用太阳能、空气源热百建立用水加热系统

太阳能系统能够减少热水供应过程中所消耗的电能, 同时太阳能具有可再生性, 与其他热源相比,其在节能环保 方面有着十分积极的影响。本项目在建筑的屋顶设置了太 阳能收集装置。太阳能可以对水资源进行加热, 在阴雨天气 甚至还可以通过空气源热水机组来保证热水的正常供应。

\section{5 结语}

在建筑设计和施工中, 给排水系统是非常重要的一个 内容, 其设计的质量直接影响工程的使用性能,并使绿色环 保理念在建筑行业得以普遍应用, 同时其在给排水设计中 也发挥着十分重要的作用, 能够更好地推动我国建筑行业 的可持续发展。

\section{参考文献:}

[1]雷国柱. 建筑给水排水设计浅析 [J]. 山西建筑, 2018,44(11):116-117.

[2]黄思玲.绿色环保理念在建筑给水排水设计中的应 用探讨[J].江西建材,2017,(03):37+44.

[3]黄思玲.绿色环保理念在建筑给水排水设计中的应 用探讨[J].江西建材,2017,(03):37+44. 